\title{
Effect of Modification of Amorphous Silica with Ammonium Agents on the Physicochemical Properties and Hydrogenation Activity of $\mathrm{Ir} / \mathrm{SiO}_{2}$ Catalysts
}

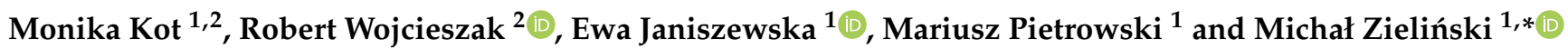 \\ 1 Faculty of Chemistry, Adam Mickiewicz University in Poznań, Uniwersytetu Poznańskiego 8, \\ 61-614 Poznań, Poland; monika.kot@amu.edu.pl (M.K.); eszym@amu.edu.pl (E.J.); \\ mariop@amu.edu.pl (M.P.) \\ 2 Univ. Lille, CNRS, Centrale Lille, Univ. Artois, UMR 8181-UCCS-Unité de Catalyse et Chimie du Solide, \\ F-59000 Lille, France; robert.wojcieszak@univ-lille.fr \\ * Correspondence: mardok@amu.edu.pl
}

check for

updates

Citation: Kot, M.; Wojcieszak, R.; Janiszewska, E.; Pietrowski, M.; Zieliński, M. Effect of Modification of Amorphous Silica with Ammonium Agents on the Physicochemical Properties and Hydrogenation Activity of $\mathrm{Ir} / \mathrm{SiO}_{2}$ Catalysts. Materials 2021, 14, 968. https:// doi.org/10.3390/ma14040968

Academic Editor: Enrica Gianotti

Received: 6 January 2021

Accepted: 15 February 2021

Published: 18 February 2021

Publisher's Note: MDPI stays neutral with regard to jurisdictional claims in published maps and institutional affiliations.

Copyright: (c) 2021 by the authors. Licensee MDPI, Basel, Switzerland. This article is an open access article distributed under the terms and conditions of the Creative Commons Attribution (CC BY) license (https:/ / creativecommons.org/licenses/by/ $4.0 /)$.

\begin{abstract}
The modification of commercial silica with solutions of $\mathrm{NH}_{4} \mathrm{~F}$ or $\mathrm{NH}_{4} \mathrm{Cl}$ salts, followed by thermal treatment, enabled generation of the acidic sites in $\mathrm{SiO}_{2}$ and changed its textural properties. The use of ammonium salts solution also caused the generation of additional porosity. Using $\mathrm{NH}_{4} \mathrm{~F}$ solution caused significant decrease in the specific surface area and the increase in the average pore diameter. The number and strength of resulting acid sites depend on the nature of anion in the applied ammonium salt and the concentration of salt solution. It has been found that the sample treated with $\mathrm{NH}_{4} \mathrm{~F}$ presented higher total acidity (TPD-NH 3 ) and the amount as well as the strength of acid sites increased with the concentration of the used modifier. As modified amorphous $\mathrm{SiO}_{2} \mathrm{materials}$ used as a support for iridium ( $\left.1 \mathrm{wt} \%, \operatorname{Ir}(\mathrm{acac})_{3}\right)$ nanoparticles permitted to obtain highly active catalysts for toluene hydrogenation under atmospheric pressure. The highest activity (expressed as the apparent rate and TOF) was obtained for iridium catalysts supported on silica modified by $\mathrm{NH}_{4} \mathrm{~F}$ with the highest acidity. The modification of silica with $\mathrm{NH}_{4} \mathrm{~F}$ favors the generation of centers able to adsorb toluene, which results in higher activity of this catalyst.
\end{abstract}

Keywords: commercial silica; modified silica; iridium catalysts; hydrogenation reaction

\section{Introduction}

Hydrogenation reactions have become industrially important since 1897, when Sabatier found out that the application of nickel as a catalyst facilitates the addition of hydrogen to molecules of gaseous hydrocarbons [1]. Nowadays, hydrogenation processes still attract considerable attention. For example, benzene hydrogenation leads to obtaining cyclohexane used in the production of nylon fibers and resins $[2,3]$.

The catalytic activity in the processes of hydrogenation depends on both the type of active phase and properties of the support used. The surface properties of support, its crystalline and porous structure affect the dispersion of active phase and determine its reducibility. For that reason, the fundamental task of heterogeneous catalysis is to find the most beneficial combination of metal active phase and support. The choice of catalyst requires many variables to be taken into account, whereas the type of catalytic process seems to be key factor.

It has been demonstrated that the support used to disperse an active phase can affect catalyst activity for aromatic hydrocarbons hydrogenation. Several authors have evidenced that the performance of metal catalysts supported on acidic supports for hydrogenation of different organic compounds-e.g., benzene, toluene, and xylene-is enhanced in comparison to catalysts on inert supports, e.g., $\mathrm{SiO}_{2}$ [4-8] and ordered mesoporous silica [9-11]. It was found that aromatics adsorbed on acid site can be hydrogenated with the activated 
hydrogen spillover from metal centers [4,5]. These results clearly indicate that the acidity of support is crucial for catalytic activity. Zeolites, as solid acids, are commonly used in catalysis. Unfortunately, their high acidity facilitates side reactions (cracking, alkylation, isomerization) and coke formation, leading to deactivation of catalyst [12]. No decrease in activity was observed when the active phase was deposited on the supports with weak and intermediate acid sites [13].

Amorphous silica materials are the most significant class of catalyst supports due to low price, hardness, chemical resistance, thermal stability, and non-toxicity. However, pure silica materials show no acidity or only low acidity. The amorphous as well as the crystalline silica (e.g., silicalite-1 with MFI structure) possess a very weak acidity due to their silanol groups. The acidity of silica depends on the amount of the silanol groups and their form (acidic silanol nests or vicinal silanols, non-acidic isolated silanols), which in turn depends on the method of its preparation or the post-synthesis treatment (e.g., calcination) [14]. The acidic properties of mesoporous silica can be modified by isomorphous substitution (e.g., obtaining AlMCM-41 [15] or AlSBA-3 [9,16]) or using post-synthesis method [17]. Some studies have also indicated that the treatment of siliceous counterparts of zeolites, particularly of MFI-type (silicalite-1), with aqueous solution of different ammonium salts and basic compound-e.g., aqueous ammonia solution, alkylamines, or allylamines-resulted in enhanced activity in the Beckmann rearrangement reaction (an acid-catalyzed rearrangement of an oxime to an amide) [18-20]. In addition, MFI-type silicalite modified with ammonium agents have been also applied for etherification of HMF [21] and acetalization of glycerol with acetone [22]. It has been shown that amorphous silica modified with aqueous solution of ammonium chloride or ammonium nitrate in presence of ammonia solution generates weak acidic properties of the material. The results presented in the literature confirmed that the presence of acid sites is essential for toluene hydrogenation [8]. The modification of silica materials using ammonium agents may be a simple, cheap, and effective route to obtain catalysts with enhanced activity for hydrogenation reactions. The modification procedure is simple and does not require multiple steps. Moreover, it involves application of nontoxic low-cost ammonium salts. For this reason, the modified supports may have potential for application in industrial-scale process.

Janiszewska et al. [22] indicated that the number and strength of acid sites generated in MFI-type silicalite by treatment with aqueous solution of ammonium salts depend on the nature of anion in the applied ammonium salt. The highest overall acidity and the higher contribution of stronger acid centers have been indicated by samples modified with aqueous solution of $\mathrm{NH}_{4} \mathrm{Cl}$ and $\mathrm{NH}_{4} \mathrm{~F}$. Additionally, the modification of silicalite- 1 by $\mathrm{NH}_{4} \mathrm{Cl}$ or $\mathrm{NH}_{4} \mathrm{~F}$ solutions caused formation of additional mesoporosity which resulted in the improvement of catalytic activity through better availability of acid centers [22]. On the other hand, in the case of cobalt catalysts for Fischer-Tropsch synthesis, silica was modified with ammonium nitrate in order to reduce surface hydroxyls resulting in weaken metal-support interaction [23], whereas the pretreatment of silica with ammonia solution led to stronger interaction between cobalt and silica [24]. Both strategies improved catalytic activities of investigated samples.

The aim of this work was to modify commercial amorphous silica using ammonium agent solutions in order to generate acid centers in starting material. The influence of the ammonium salts used $\left(\mathrm{NH}_{4} \mathrm{Cl}\right.$ or $\left.\mathrm{NH}_{4} \mathrm{~F}\right)$ and its concentration $(0.1 \mathrm{M}$ or $1.0 \mathrm{M})$ on the acidity and textural properties of the obtained amorphous silica was investigated. It was the first attempt to use $\mathrm{NH}_{4} \mathrm{~F}$ as a modifier of amorphous silica to generate its acidic properties. The obtained silica materials were used as supports for iridium catalysts. The effect of support acidity on the activity of catalysts for toluene hydrogenation was studied.

2. Materials and Methods

\subsection{Supports and Catalysts Preparation and Activation}

Amorphous silica (Polish Chemical Reagents, Gliwice, Poland) was modified with 0.1 and $1.0 \mathrm{M}$ solutions of ammonium chloride $\left(\mathrm{NH}_{4} \mathrm{Cl}\right.$-Aldrich, Saint Louis, Missouri, 
USA) and ammonium fluoride ( $\mathrm{NH}_{4} \mathrm{~F}$-Polish Chemical Reagents, Gliwice, Poland). The samples of silica were calcined before modification for $3 \mathrm{~h}$ at $550{ }^{\circ} \mathrm{C}$. A portion of silica $(1 \mathrm{~g})$ was mixed with $100 \mathrm{~cm}^{3}$ of aqueous solution of $\mathrm{NH}_{4} \mathrm{Cl}$ or $\mathrm{NH}_{4} \mathrm{~F}$. The obtained mixture was stirred under reflux at temperature $60^{\circ} \mathrm{C}$ for $1 \mathrm{~h}$. After the treatment, the silica modified materials were filtered, washed, and dried at RT (room temperature). Finally, the samples were calcined in the muffle furnace in the air $\left(550{ }^{\circ} \mathrm{C} ; 3 \mathrm{~h}\right)$. The resulting samples were labeled as $\mathrm{SiO}-\mathrm{F}-\mathrm{x}$ (sample modified with solution of ammonium fluoride) and $\mathrm{SiO}-\mathrm{Cl}-\mathrm{x}$ (sample modified with solution of ammonium chloride) where $\mathrm{x}$ means concentration of modifying agent. For comparison, the unmodified silica, labeled as $\mathrm{SiO}$ was also used as a support.

Iridium was deposited on silica supports by conventional impregnation method using iridium acetylacetonate $\left(\operatorname{Ir}(\mathrm{acac})_{3}\right.$-Aldrich, Saint Louis, MO, USA) as a metal precursor. The metal precursor was dissolved in methanol (Polish Chemical Reagents, Gliwice, Poland) and the calcined support was added to the iridium solution (the amount of iridium precursor was calculated to achieve metal loading of $1 \mathrm{wt} \%$ ). After stirring the solvent was removed using rotary evaporator and the catalysts were dried $\left(105^{\circ} \mathrm{C} ; 24 \mathrm{~h}\right)$. The obtained materials were labeled as Ir-SiO, Ir-SiO-Cl-0.1, Ir-SiO-F-0.1.

Prior to the measurements of hydrogen chemisorption, as well as before the measurements by low-temperature $\mathrm{N}_{2}$ adsorption/desorption (BET), X-ray photoelectron spectroscopy (XPS), X-ray powder diffraction (XRD), X-ray fluorescence (XRF) and Fouriertransform infrared spectroscopy (FTIR) measurements, each precursor-impregnated support was placed in a fixed-bed flow reactor and reduced in hydrogen flow (Linde, $50 \mathrm{~cm}^{3} \mathrm{~min}^{-1}, 400{ }^{\circ} \mathrm{C}, 2 \mathrm{~h}$ ). Only for temperature-programmed reduction with hydrogen $\left(\mathrm{TPR}-\mathrm{H}_{2}\right)$ measurement, dried precursors of catalysts were used.

\subsection{Characterization of Supports and Catalysts}

The Brunauer-Emmet-Teller (BET,) surface areas $\left(\mathrm{S}_{\mathrm{BET}}\right)$ were determined by lowtemperature $\left(-196^{\circ} \mathrm{C}\right)$ nitrogen adsorption/desorption using a Micromeritics model ASAP 2010 sorptometer (Micromeritics, Norcross, GA, USA). Total pore volume and average pore diameter were determined by the Barrett-Joyner-Halenda (BJH) method.

The temperature-programmed desorption of ammonia measurements $\left(\mathrm{NH}_{3}-\mathrm{TPD}\right)$ were carried out on Micromeritics (Norcross, GA, USA) model Pulse ChemiSorb 2705 instrument. A portion of the support $(\sim 500 \mathrm{mg})$ was activated in-situ for $1 \mathrm{~h}$ in He (Linde) at the rate of $10{ }^{\circ} \mathrm{C} \min ^{-1}$ up to $450{ }^{\circ} \mathrm{C}$. Next it was cooled to $100{ }^{\circ} \mathrm{C}$ and contacted with ammonia for $10 \mathrm{~min}$ at a flow rate of $10 \mathrm{~cm}^{3} \cdot \mathrm{min}^{-1}$ followed by flushing with helium $\left(30 \mathrm{~cm}^{3} \cdot \mathrm{min}^{-1} ; 1 \mathrm{~h}\right)$. Then, the $\mathrm{NH}_{3}$-TPD analysis was performed in the temperature range of $100-500{ }^{\circ} \mathrm{C}$ with a heating rate of $10^{\circ} \mathrm{C} \mathrm{min}^{-1}$ using TCD detector. The $\mathrm{NH}_{3}$-TPD profiles were normalized to the same sample weight $(1 \mathrm{~g})$. The calibration was performed with a calibrated gas loop by dispensing $1 \mathrm{~cm}^{3} \mathrm{NH}_{3}$ into the helium flow.

FTIR analysis was performed using FTS 3000 Bio-Rad (Bio-Rad, CA, USA) spectrophotometer connected to a conventional vacuum system. Detailed experimental procedure of FTIR analysis is presented in Supplementary Materials. Pyridine adsorption (6.0 mbar) was carried out at $50{ }^{\circ} \mathrm{C}$ for $10 \mathrm{~min}$. Spectra were recorded after evacuation at 50,75 and $100{ }^{\circ} \mathrm{C}$. Toluene adsorption ( $5.0 \mathrm{mbar}$ ) was carried out at room temperature for $10 \mathrm{~min}$. Spectra were recorded after evacuation at RT.

XRD analysis was performed in the $2 \Theta$ range between $10^{\circ}$ and $60^{\circ}$ on a Bruker AXS D8 Advance (Billerica, MA, USA) diffractometer with Ni-filtered CuK $\alpha$ radiation $(\lambda=1.54056 \AA)$.

Iridium content in catalysts after activation was determined by XRF measurements using energy dispersive micro X-ray fluorescence spectrometer M4 TORNADO (Bruker, Billerica, MA, USA).

Measurements of TPR- $\mathrm{H}_{2}$ were carried out on Pulse ChemiSorb 2705 (Micromeritics, Norcross, GA, USA) instrument. Dried metal precursor-impregnated supports ( $\sim 50 \mathrm{mg})$ were reduced in the flow of $10 \mathrm{vol} \% . \mathrm{H}_{2}$-Ar (Linde) at the flow rate of $30 \mathrm{~cm}^{3} \mathrm{~min}^{-1}$ in the 
temperature range from 50 to $700{ }^{\circ} \mathrm{C}$ with the heating rate of $10^{\circ} \mathrm{C} \mathrm{min}^{-1}$. In the TPR- $\mathrm{H}_{2}$ studies, a quartz sand (Aldrich) impregnated with iridium acetylacetonate was used as a reference material. All TPR-H $\mathrm{H}_{2}$ profiles have been normalized to the same sample weight.

Chemisorption of $\mathrm{H}_{2}$ experiments were performed on an ASAP 2010C (Micromeritics, Norcross, GA, USA) sorptometer. Detailed experimental procedure of $\mathrm{H}_{2}$ chemisorption analysis is presented in Supplementary Materials.

Iridium surface area $\left(S, \mathrm{~m}^{2} \mathrm{~g}_{\mathrm{Ir}}{ }^{-1}\right)$ was calculated using the following equation [25]

$$
S=\frac{v_{m} \cdot N_{A} \cdot n \cdot a_{m} \cdot 100}{22,414 \cdot m \cdot w t}
$$

where $v_{m}$-volume of adsorbed hydrogen $\left(\mathrm{cm}^{3}\right) ; N_{A}$ is Avogadro's number $\left(6.022 \times 10^{23} \mathrm{~mol}^{-1}\right)$; $n$-chemisorption stoichiometry $(n=2) ; a_{m}$-surface area $\left(\mathrm{m}^{2}\right)$ occupied by an iridium atom; $m$-mass of sample $(\mathrm{g}) ;$ wt $(\%)$-iridium loading.

The dispersion $(D)$ of iridium phase was calculated according to the formula

$$
D=\frac{S \cdot M}{a_{m} \cdot N_{A}}
$$

where $S$-the iridium surface area; $M$-iridium atomic weight; $N_{A}$-Avogadro's number; and $a_{m}$-surface covered by one iridium atom. The metal content determined by X-ray fluorescence measurements was taken in the calculation of the dispersion.

The average iridium particle size $(P, \mathrm{~nm})$ was calculated using the following equation

$$
P=\frac{6000}{S \cdot \rho}
$$

where $S$-the iridium surface area; $\rho$-metal density $\left(\mathrm{g} \cdot \mathrm{cm}^{-3}\right)$.

$X$-ray photoelectron spectroscopy (XPS) analysis of the iridium catalysts was carried out with a Kratos Axis Ultra spectrometer (Kratos Analytical, Manchester, UK). The excitation source was monochromatized aluminum X-ray source $(\mathrm{Al} \mathrm{K} \alpha(1486.6 \mathrm{eV}))$ operated at $10 \mathrm{~mA}$ and $15 \mathrm{kV}$. The spectra were referenced to the binding energy of C (1 s) $(284.6 \mathrm{eV})$. Spectroscopic data were processed by the CasaXPS ver. 2.3.17PR1.1 software (Casa Software Ltd., Teignmouth, UK), using a peak-fitting routine with Shirley background.

Toluene hydrogenation was performed at atmospheric pressure using a fixed-bed flow reactor and $\mathrm{H}_{2}$ as a carrier gas. The scheme (Figure S1) of the setup used for toluene hydrogenation and detailed experimental procedure are presented in Supplementary Materials.

The catalytic activity is presented as turnover frequency (TOF, $\mathrm{min}^{-1}$ _in moles of toluene reacted per surface iridium atoms for $1 \mathrm{~min}$ ) or as apparent rate $\left(r_{t}\right)$ calculated according to the following equation [26]

$$
r_{t}=\frac{F Y C}{N}
$$

where $F$-total flow rate $\left(\mathrm{cm}^{3} \mathrm{~min}^{-1}\right) ; Y$-conversion of toluene; $C$-concentration of toluene in the feed $\left(\mathrm{mol}_{\mathrm{Tl}} \mathrm{cm}^{3}\right)$; and $\mathrm{N}$-iridium content $\left(\mathrm{mol}_{\mathrm{Ir}}\right)$ in the sample. Turnover frequency (abbreviation TOF) was calculated by dividing the number of toluene molecules converted per unit time by the number of active iridium atoms.

\section{Results and Discussion}

\subsection{Characterization of the Modified Amorphous Silica}

The amorphous silica was modified with the use of ammonium salts solutions in order to generate acid centers on its surface. For this purpose, $\mathrm{NH}_{4} \mathrm{Cl}$ and $\mathrm{NH}_{4} \mathrm{~F}$ solutions with concentrations of 0.1 and $1.0 \mathrm{M}$ were used. The modified silica materials obtained in the work are new systems that have never been used as supports in catalysis. Hence, the characteristics of the porosity and the specific surface are a very important parameter 
characterizing new supports. Based on low-temperature nitrogen adsorption-desorption measurements, the textural properties of unmodified and modified silicas were determined. The obtained samples contained mesopores in the size range of 3 to $13 \mathrm{~nm}$, while the BET surface area changed from 311 to $117 \mathrm{~m}^{2} \cdot \mathrm{g}^{-1}$ (Table 1).

Table 1. Physicochemical properties of the unmodified and modified silicas.

\begin{tabular}{|c|c|c|c|c|c|c|}
\hline \multirow[b]{2}{*}{ Sample Code } & \multicolumn{6}{|c|}{ Physical Characterization of Supports } \\
\hline & $\begin{array}{l}\text { Activation } \\
\text { Conditions }\end{array}$ & $\mathrm{S}_{\mathrm{BET}}, \mathrm{m}^{2} \cdot \mathrm{g}^{-1}$ & $\begin{array}{c}\text { Total Pore } \\
\text { Volume, } \mathrm{cm}^{3} \cdot \mathrm{g}^{-1}\end{array}$ & $\begin{array}{l}\text { Average Pore } \\
\text { Diameter, nm }\end{array}$ & $\begin{array}{c}\text { Acid Centers } \\
\mu^{(a)} \\
\mathrm{mol} \cdot \mathrm{g}^{-1}\end{array}$ & $\begin{array}{c}\text { Density of } \\
\text { Acid Sites (a), } \\
\mu \mathrm{mol} \cdot \mathrm{m}^{-2}\end{array}$ \\
\hline $\mathrm{SiO}$ & \multirow{5}{*}{$\begin{array}{l}\text { calcination } \\
(\text { air, } 3 \mathrm{~h}, \\
\left.550^{\circ} \mathrm{C}\right)\end{array}$} & 311 & 0.23 & 3.0 & 73.5 & 0.24 \\
\hline $\mathrm{SiO}-\mathrm{Cl}-0.1$ & & 291 & 0.24 & 3.1 & 154.7 & 0.53 \\
\hline $\mathrm{SiO}-\mathrm{Cl}-1.0$ & & 183 & 0.34 & 6.5 & 218.7 & 1.19 \\
\hline SiO-F-0.1 & & 263 & 0.25 & 3.5 & 169.3 & 0.64 \\
\hline $\mathrm{SiO}-\mathrm{F}-1.0$ & & 117 & 0.41 & 13.0 & 291.9 & 2.49 \\
\hline
\end{tabular}

(a) Concentration and density of acid sites were determined on the basis of $\mathrm{NH}_{3}$-TPD experiments.

The studies of low-temperature $\mathrm{N}_{2}$ adsorption indicate that the use of the modifiers with a concentration of $1.0 \mathrm{M}$ caused generation of additional porosity-the value of the $\mathrm{S}_{\text {BET }}$ drops from $311 \mathrm{~m}^{2} \cdot \mathrm{g}^{-1}$ for the initial silica to $183 \mathrm{~m}^{2} \cdot \mathrm{g}^{-1}$ for the SiO-Cl-1.0 sample and $117 \mathrm{~m}^{2} \cdot \mathrm{g}^{-1}$ for SiO-F-1.0 with a simultaneous increase in the average pore diameter to 6.5 and $13 \mathrm{~nm}$ for SiO-Cl-1.0 and SiO-F-1.0, respectively. The obtained results also show that the use of $\mathrm{NH}_{4} \mathrm{~F}$ solution causes a higher decrease of the $\mathrm{S}_{\mathrm{BET}}$ and an over fourfold increase in the average pore diameter in relation to the unmodified silica. The use of modifiers with a lower concentration $(0.1 \mathrm{M})$ does not lead to such drastic changes both in the $\mathrm{S}_{\mathrm{BET}}$ and in the porous properties. The textural changes are particularly seen in the shape of the $\mathrm{N}_{2}$ adsorption-desorption isotherms-Figure 1.

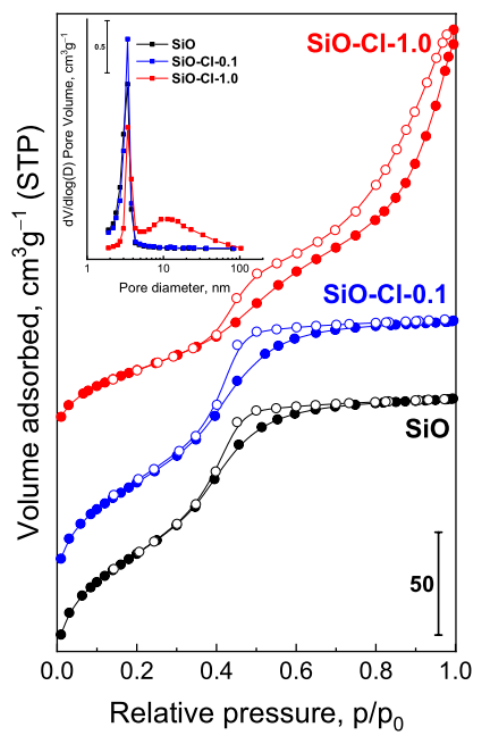

a)

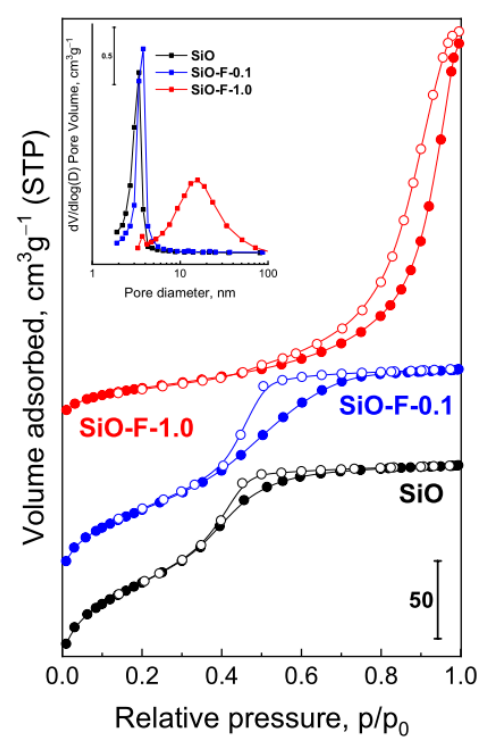

b)

Figure 1. Low-temperature $\mathrm{N}_{2}$ adsorption/desorption isotherms and pore size distribution (inset) of unmodified silica and silica samples modified by $\mathrm{NH}_{4} \mathrm{Cl}(\mathbf{a})$ and $\mathrm{NH}_{4} \mathrm{~F}(\mathbf{b})$.

The initial $\mathrm{SiO}_{2}$, according to the new IUPAC classification, is characterized by type IV(a) isotherm and H2(a) hysteresis loop [27]. The shape of isotherm is characteristic of mesoporous materials having a pore system for which network effects play a significant role. The very steep desorption branch, which is a characteristic feature of H2(a) loops, 
can be attributed either to pore-blocking/percolation in a narrow range of pore necks or to cavitation-induced evaporation. $\mathrm{SiO}$ material is characterized by a very narrow pore size distribution, mainly in the range of $2-4 \mathrm{~nm}$ (with average pore size of $3.0 \mathrm{~nm}$ ). The initial silica and samples after modification with the $0.1 \mathrm{M}$ ammonium solutions show similar adsorption isotherms. The slightly larger hysteresis loop for samples modified with $0.1 \mathrm{M}$ solutions in comparison to the initial silica is due to the formation of new mesopores during the modification process. The position of hysteresis loop in the same range of $\mathrm{p} / \mathrm{p}_{0}=0.4-0.7$ indicates the similar pore sizes of the initial and modified samples that is consistent with pore size distribution profiles (Figure 1, inset). The shape of the $\mathrm{N}_{2}$ adsorption-desorption isotherms change after using ammonium salts with a concentration of $1.0 \mathrm{M}$. The desorption isotherm of SiO-Cl-1.0 sample has an inflection in the relative pressure $\mathrm{p} / \mathrm{p}_{0}=0.4-1.0$ indicating the presence of pores of different sizes. The pore size distribution curve (Figure 1a, inset) shows that apart the pores with a size of $\sim 3 \mathrm{~nm}$, there are additional pores with a size of $\sim 10 \mathrm{~nm}$. Such an inflection was not recorded for the SiO-F-1.0 system, the hysteresis loop is shifted to higher $\mathrm{p} / \mathrm{p}_{0}$, and the pore size distribution was in the range of 3-50 nm with a maximum of $\sim 13 \mathrm{~nm}$-Figure $1 \mathrm{~b}$. For systems modified with $1.0 \mathrm{M}$ solutions, all isotherms are of type IV(a) and hysteresis loops of type H2(b). The presence of hysteresis loop of type $\mathrm{H} 2$ (b) and parallel adsorption and desorption branches $\left(\mathrm{p} / \mathrm{p}_{0}\right.$ 0.7-0.9) indicates that the pores of obtained materials have a cylindrical shape, while the fact that the loop closes at $\mathrm{p} / \mathrm{p}_{0}=0.4$ suggests the presence of small cone-shaped pores.

$\mathrm{NH}_{3}$-TPD analysis was performed to characterize acidic properties of samples, assess the acid strength distribution, and determine the concentration of acid sites. The $\mathrm{NH}_{3}-\mathrm{TPD}$ profiles are presented in Figure 2 and results of their deconvolution in Figure S2.

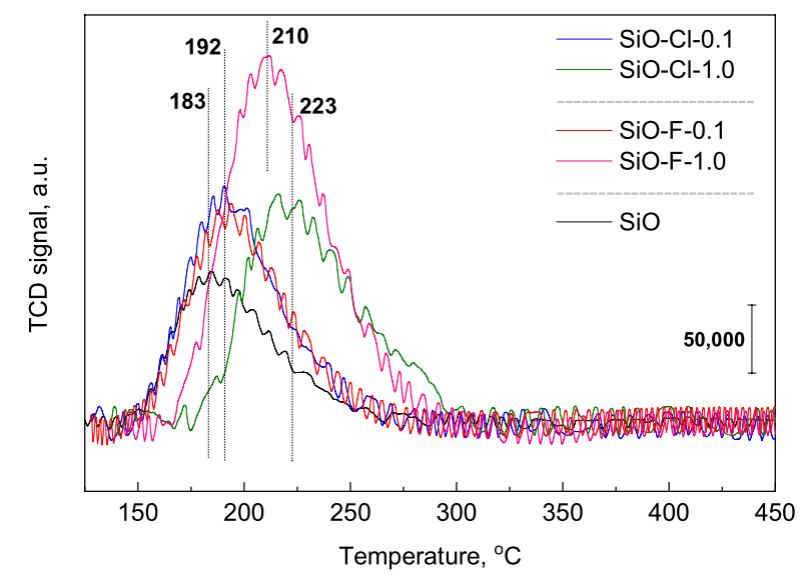

Figure 2. $\mathrm{NH}_{3}-\mathrm{TPD}$ profiles of silica samples calcined at $550{ }^{\circ} \mathrm{C}$.

Based on the shape of the $\mathrm{NH}_{3}$-TPD profiles it can be concluded that the investigated samples contain acid centers of different strengths. The traditional classification [28] describes the existence of two kinds of acid centers: weak acid centers assigned to lowtemperature peaks (below $400{ }^{\circ} \mathrm{C}$ ) and strong acid centers ascribed to high-temperature peaks (above $400{ }^{\circ} \mathrm{C}$ ). The low-temperature peaks refer to desorption of ammonia from weakly acidic silanol groups and weak Lewis acid centers, while high-temperature peaks correspond to desorption of ammonia from strong Brønsted and Lewis acid sites [28]. The $\mathrm{NH}_{3}$-TPD profiles in the case of our samples indicate only desorption peaks below $400{ }^{\circ} \mathrm{C}$ attributed to weak acid sites. Due to the fact that the desorption maxima for all samples were recorded at different temperature, the deconvolution of the peaks was applied. Moreover, a new specific classification of the strength of acid sites, that will be more suitable for presented silica materials, was introduced. The desorption peak at about $180{ }^{\circ} \mathrm{C}$ can be assigned to weak acid sites, whereas peaks at and above $200^{\circ} \mathrm{C}$ refer to medium strength and strong acid sites, respectively. The concentration of surface acid centers was calculated (Table 1) on the basis of the $\mathrm{NH}_{3}$-TPD profiles and after deconvolution of 
the profiles (Figure S2), the concentration of the weak, medium, and strong acid centers was evaluated (Figure 3). The modification of pristine support causes the formation of additional acid centers on its surface. The number and the strength of formed acid sites depends on the type and concentration of ammonium agent applied for a modification. The initial silica ( $\mathrm{SiO})$ shows a slight acidity $\left(73.5 \mu \mathrm{mol} \cdot \mathrm{g}^{-1}\right)$ and the modification of its surface with $0.1 \mathrm{M}$ solutions leads to the generation of additional acid centers, especially of low and medium strength. In the case of samples modified with $1.0 \mathrm{M}$ solutions, an increase in the concentration of strong acid centers is observed with a simultaneous decrease in the contribution of weak acid centers-Figure 3 .

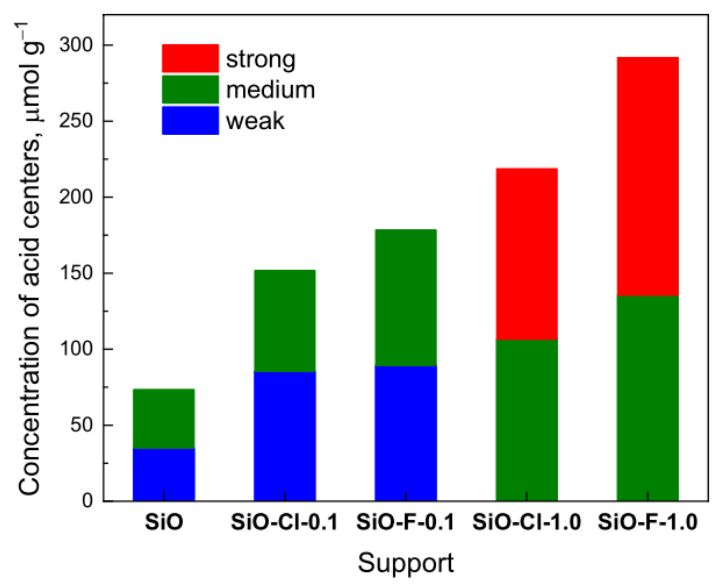

Figure 3. Concentration of different types of acid centers on the surface of indicated silica materials calculated from $\mathrm{NH}_{3}$-TPD studies.

Based on TPD- $\mathrm{NH}_{3}$ the strength and concentration of acidic centers on the surface of investigated silica materials were determined whereas the nature of acid sites was characterized using FTIR spectroscopy using pyridine as a probe molecule. In Figure 4, FTIR spectra recorded after pyridine adsorption on the surface of pristine and selected modified silica supports are presented.

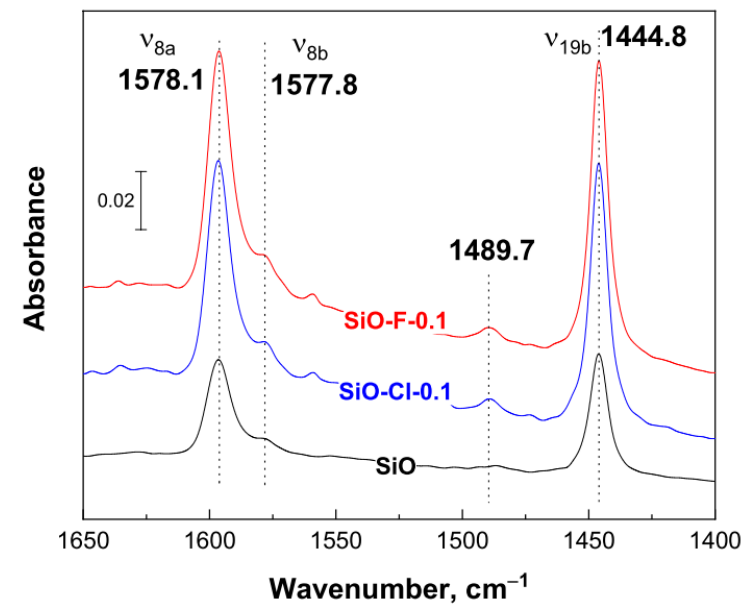

Figure 4. FTIR spectra of pyridine adsorbed on the modified and unmodified $\mathrm{SiO}_{2}$ after evacuation at $50{ }^{\circ} \mathrm{C}$.

In the spectra of the starting silica as well as for materials modified with $0.1 \mathrm{M}$ solutions of ammonium salts bands characteristic of pyridine coordinately bounded to Lewis acid centers were observed: $v_{19 \mathrm{~b}}$ at 1444.8 and $v_{8 \mathrm{a}}$ at $1578.1 \mathrm{~cm}^{-1}$. No presence of Brønsted acid centers $\left(v_{19 b}\right.$ at $1532 \mathrm{~cm}^{-1}$ and $v_{8 \mathrm{a}}$ at $\left.1643 \mathrm{~cm}^{-1}\right)$ was found [29]. The band at $1444.8 \mathrm{~cm}^{-1}$ 
can also originate from Py hydrogen-bounded to surface hydroxyl or silanol groups [30]. A band at $1578.1 \mathrm{~cm}^{-1}$ corresponds to pyridine bounded to weak Lewis acid sites [31]. Weak band at $1489.7 \mathrm{~cm}^{-1}$, seen only for the samples after modification, is associated with both Lewis and Brønsted acid sites [31]. Because of the lack of a band at $1532 \mathrm{~cm}^{-1}$, it could be concluded that the band at $1489.7 \mathrm{~cm}^{-1}$ originates only from Lewis acid centers. The same bands are presented in the spectra of samples modified with $1.0 \mathrm{M}$ solutions of ammonium salts (spectra not shown).

Summarizing the results of the research on the modification of amorphous silica with the use of ammonium salts of various concentrations, it can be concluded that the modification with $\mathrm{NH}_{4} \mathrm{Cl}$ and $\mathrm{NH}_{4} \mathrm{~F}$ solutions with concentrations of $0.1 \mathrm{M}$ allows to obtain mesoporous supports with a surface area comparable to the original silica, and their modification leads to the generation on their surface of the Lewis type acid centers of weak and medium strength. Hence, in the further part of the research, these systems were selected as supports for the iridium active phase.

\subsection{Iridium Catalysts}

Selected supports were used to prepare iridium catalysts. The precursor of the active phase was iridium acetylacetonate $\left(\operatorname{Ir}(\mathrm{acac})_{3}\right)$ and metal loading was $1 \mathrm{wt} \%$. The X-ray fluorescence $(X R F)$ measurements of all the iridium catalysts have indicated the similar amount of iridium but lower amount than the intended ones-Table 2 . The bare silica showed the greatest difference in the amount of iridium in relation to the intended amount. In the further part of the research (dispersion of the active phase and studies of hydrogenation activity), the iridium content determined on the basis of XRF was taken into consideration.

Table 2. Physicochemical properties of iridium catalysts.

\begin{tabular}{|c|c|c|c|c|c|}
\hline \multirow[b]{2}{*}{ Sample Code } & \multicolumn{4}{|c|}{ Physicochemical Characterization of Iridium Catalysts } & \multirow[b]{2}{*}{$\underset{\%}{\text { Metal Content }}{ }^{(a)}$} \\
\hline & $\begin{array}{l}\text { Activation } \\
\text { Conditions }\end{array}$ & $\mathrm{S}_{\mathrm{BET}}, \mathrm{m}^{2} \cdot \mathrm{g}^{-1}$ & $\begin{array}{c}\text { Total Pore } \\
\text { Volume, } \mathrm{cm}^{3} \cdot \mathrm{g}^{-1}\end{array}$ & $\begin{array}{l}\text { Average Pore } \\
\text { Diameter, nm }\end{array}$ & \\
\hline $\mathrm{Ir}-\mathrm{SiO}$ & \multirow{3}{*}{$\begin{array}{l}\text { reduction }\left(\mathrm{H}_{2}, 2 \mathrm{~h} \text {, }\right. \\
\left.400{ }^{\circ} \mathrm{C}\right)\end{array}$} & 277 & 0.25 & 3.6 & 0.71 \\
\hline $\mathrm{Ir}-\mathrm{SiO}-\mathrm{Cl}-0.1$ & & 275 & 0.23 & 3.1 & 0.76 \\
\hline $\mathrm{Ir}-\mathrm{SiO}-\mathrm{F}-0.1$ & & 246 & 0.26 & 3.4 & 0.81 \\
\hline
\end{tabular}

(a) Metal content determined by XRF method.

Temperature programmed reduction with hydrogen (TPR- $\left.\mathrm{H}_{2}\right)$ was used to determine the temperature needed to decompose iridium precursor ligands with hydrogen and remove them from the catalyst surface. TPR- $\mathrm{H}_{2}$ studies were carried out on dried samples and reduction profiles of fresh catalysts precursors dried at $105^{\circ} \mathrm{C}$ are presented in Figure 5 .

The TPR- $\mathrm{H}_{2}$ profile of iridium precursor $\left(\operatorname{Ir}(\mathrm{acac})_{3}\right)$ indicates one peak with maximum at the temperature $277^{\circ} \mathrm{C}$ with small shoulders at $\sim 300{ }^{\circ} \mathrm{C}$. However, $\operatorname{Ir}(\text { acac })_{3}$ deposited on modified and unmodified silica materials shows hydrogen consumption with two separated maxima at $\sim 300{ }^{\circ} \mathrm{C}$ and $\sim 430{ }^{\circ} \mathrm{C}$, which indicates two-steps decomposition and reduction of active phase precursor. No hydrogen consumption was seen in profiles of the supports (data not presented), which, as expected, proves that the supports were irreducible. According to the authors of [32], thermal decomposition of acac ligands in Ir-acac ${ }_{x}$ species took place at a temperature of about $320^{\circ} \mathrm{C}$. It indicates that the peak at $\sim 300^{\circ} \mathrm{C}$ in the presented profiles originates from the decomposition of acac ligands. The peak with the maximum at $380-400{ }^{\circ} \mathrm{C}$, visible in presented profiles could be attributed to a reductive decomposition of Ir-acac $x$ species [32]. The deconvolution of the reduction profiles of investigated samples in the $200-400{ }^{\circ} \mathrm{C}$ range (Figure S3) indicates additionally presence of iridium oxide particles on the catalyst surface with the maximum reduction at $\sim 275^{\circ} \mathrm{C}$. As reported by the authors [33], this peak can be identified as well-dispersed iridium species. The presence of iridium oxide particles is probably due to the degradation of part of $\mathrm{Ir}$ (acac) $)_{3}$ to $\mathrm{IrO}_{2}$ during drying of the catalysts. The $\mathrm{TPR}-\mathrm{H}_{2}$ results showed that relatively high temperatures are needed for reductive decomposition of acac ligands in 
iridium catalysts supported on modified and unmodified silicas. However, the reduction temperature of $400{ }^{\circ} \mathrm{C}$ used in the work is sufficient for the decomposition and reduction of the metallic phase precursor. In contrast to the TPR- $\mathrm{H}_{2}$ measurements, the catalyst activation (Section 2.1) was carried out in pure hydrogen and in extended time (2 h), which allowed the complete transition of the active phase precursor to the metallic iridium. In addition, the carried out TPR- $\mathrm{H}_{2}$ measurements of the reduced catalysts showed no reduction peaks indicating the presence of non-reduced active phase.

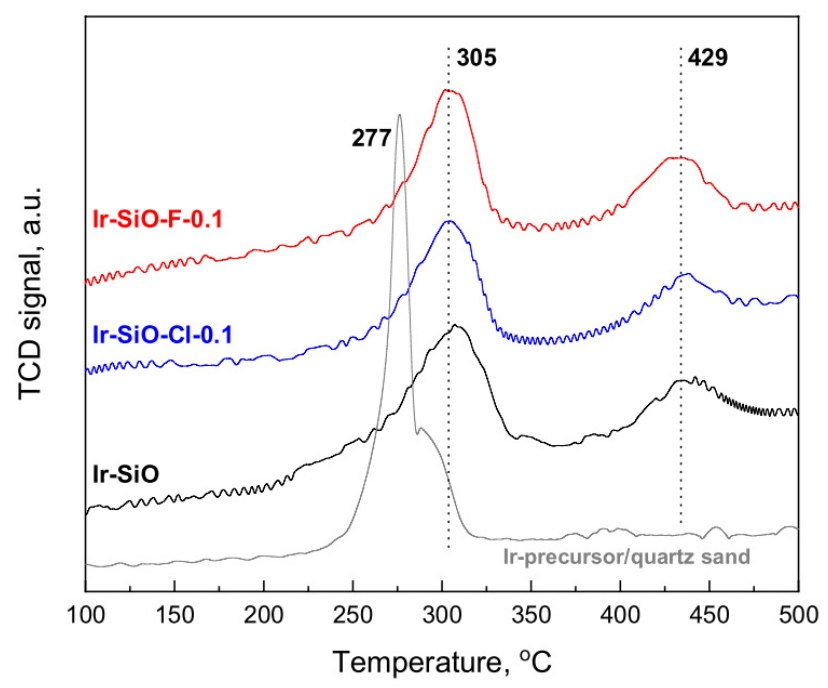

Figure 5. Temperature programmed reduction profiles of the dried catalysts and iridium precursor $\left(\operatorname{Ir}(\mathrm{acac})_{3}\right)$. Signal intensity was standardized to the same samples weight $(100 \mathrm{mg})$.

Measurements of low-temperature nitrogen adsorption/desorption were carried out for catalysts reduced at $400{ }^{\circ} \mathrm{C}$. Table 2 shows the specific surface area, total pore volume, and average pore diameter of the catalysts investigated. The $\mathrm{N}_{2}$ adsorption/desorption isotherms of iridium catalysts strongly resemble those obtained for supports, therefore the isotherms of catalysts are shown in Supplementary Material (Figure S4).

The low-temperature nitrogen adsorption-desorption isotherms were used to calculate surface area of supports and iridium catalysts-Figure 6. As already mentioned in the discussion of the results of $\mathrm{N}_{2}$ adsorption-desorption measurements of supports (Section 3.1) the $\mathrm{S}_{\mathrm{BET}}$ of supports decreases from $311 \mathrm{~m}^{2} \cdot \mathrm{g}^{-1}$ for unmodified silica to $263 \mathrm{~m}^{2} \cdot \mathrm{g}^{-1}$ for SiO-F-0.1. A similar tendency is observed in the case of the surface area of catalysts. However, the catalysts show always somewhat lower surface area than the surface area of relevant supports. The decrease in surface area of the catalysts is a result of the deposition of active phase and additional thermal and wet treatment during catalyst preparation. The impregnation of the supports and the subsequent thermal treatment of the catalysts also affect the average pore diameter, which is particularly seen for unmodified silica-Figure 6. For the latter sample, the largest decrease in BET surface area as well as some increase in average pore diameter was observed. 


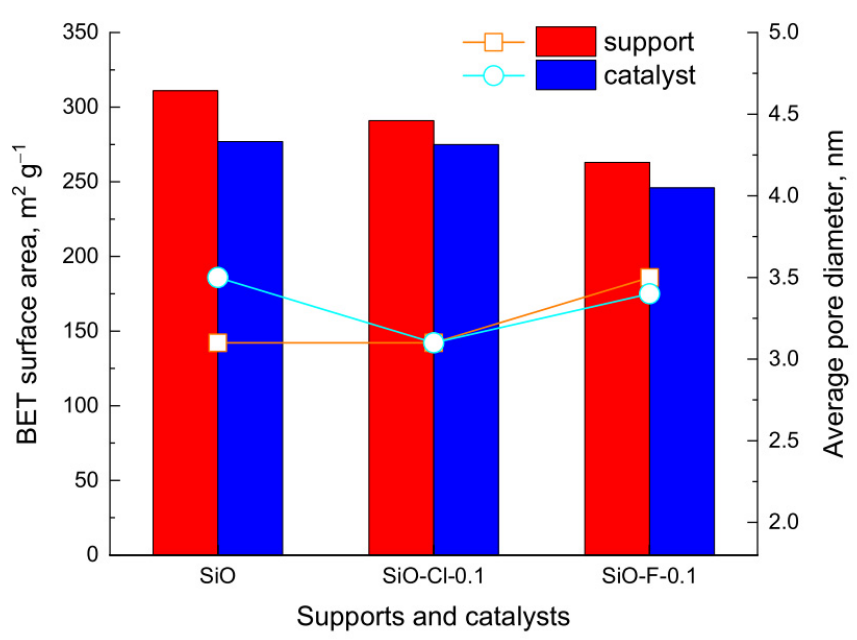

Figure 6. BET surface areas (bars) and average pore diameters (dots) of supports (red) and iridium catalysts (blue).

In Figure 7 are presented $\mathrm{X}$-ray patterns of unmodified silica and iridium catalysts. The wide reflection in the $2 \Theta$ range of $15-30^{\circ}$ observed for all materials is ascribed to amorphous silica.

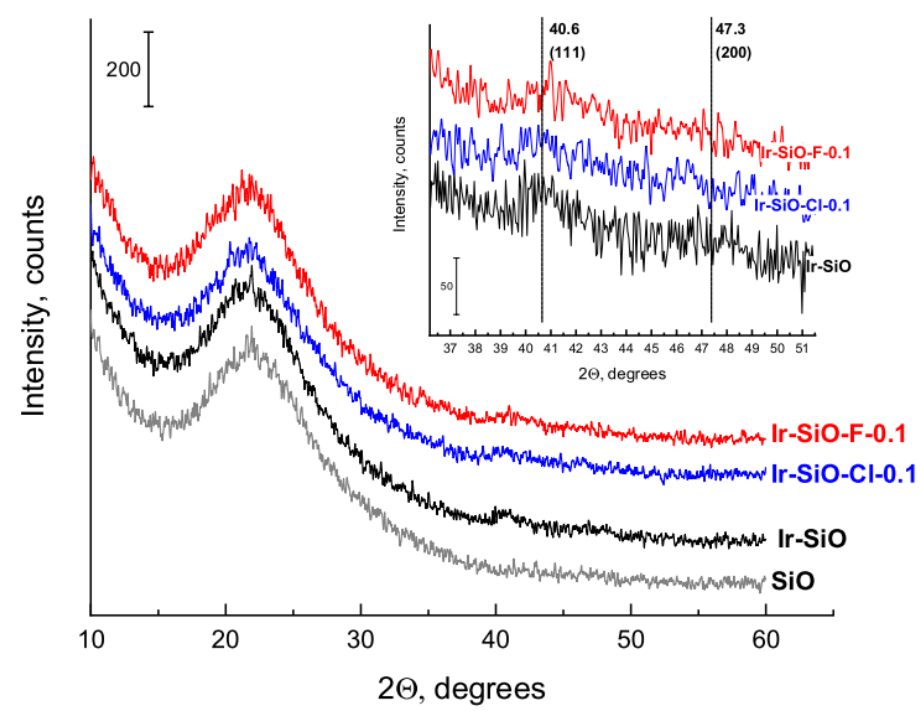

Figure 7. X-ray diffraction patterns of unmodified silica and iridium catalysts reduced at $400{ }^{\circ} \mathrm{C}$.

The XRD patterns of iridium catalysts show weak reflections at $2 \Theta=40.6^{\circ}(111)$ and $47.3^{\circ}(200)$ corresponding to metallic iridium with a fcc structure [34]. The intensity of the reflections is very small, although noticeable, which for such a low loading of the support surface may indicate a crystallite size of about $5 \mathrm{~nm}$. Particularly visible is the reflex at $2 \Theta=40.6^{\circ}$ for Ir-SiO catalyst. It indicates that the modification of the silica support leads to a better dispersion of active phase for Ir-SiO-Cl-0.1 and Ir-SiO-F-0.1 catalysts. The XRD results were confirmed by hydrogen chemisorption measurements.

As the iridium loading was very low $(0.7-0.8 \mathrm{wt} \%)$, therefore confirmation of $\operatorname{Ir}^{0}$ phase by XRD analysis was difficult. For this reason, a suitable method that provides detailed information about iridium particle size can be hydrogen chemisorption measurements. The experiments were performed in a volumetric system at $35^{\circ} \mathrm{C}$. Before the measurements, each catalyst was activated in-situ at $360{ }^{\circ} \mathrm{C}$ in $\mathrm{H}_{2}$ flow. On the basis of hydrogen being adsorbed irreversibly, calculations of average particle size and dispersion of active phase were performed. Results of the calculations are presented in Table 3. 
Table 3. $\mathrm{H}_{2}$-chemisorption data and activity of indicated catalysts.

\begin{tabular}{|c|c|c|c|c|c|c|}
\hline \multirow{3}{*}{ Sample Code } & \multicolumn{5}{|c|}{ Hydrogen Chemisorption Data for Ir/SiO Catalysts (a) } & \multirow{3}{*}{$\begin{array}{c}\text { Toluene Hydrogenation } \\
\text { Apparent Rate at } 150^{\circ} \mathrm{C}, \\
\operatorname{mol}_{\mathrm{T}} \cdot \mathrm{mol}_{\mathrm{Ir}}{ }^{-1} \cdot \mathrm{min}^{-1}\end{array}$} \\
\hline & \multicolumn{3}{|c|}{ Volume Adsorbed, $\mathrm{cm}^{3} \cdot \mathrm{g}^{-1}$} & \multirow{2}{*}{$\begin{array}{c}\text { Dispersion, } \% \\
\text { D }\end{array}$} & \multirow{2}{*}{$\begin{array}{c}\text { Average Ir } \\
\text { Particle Size, } \mathrm{nm}\end{array}$} & \\
\hline & $\mathbf{H}_{\mathbf{t}}$ & $\mathbf{H}_{\mathbf{r}}$ & $\mathbf{H}_{\text {irr }}$ & & & \\
\hline Ir-SiO & 0.17 & 0.09 & 0.08 & 19 & 5.8 & 7.7 \\
\hline Ir-SiO-Cl-0.1 & 0.20 & 0.10 & 0.10 & 23 & 4.9 & 9.7 \\
\hline Ir-SiO-F-0.1 & 0.23 & 0.12 & 0.11 & 24 & 4.8 & 15.8 \\
\hline
\end{tabular}

(a) Dispersion determined by $\mathrm{H}_{2}$ chemisorption. $\mathrm{H}_{\mathrm{t}}$-total adsorbed hydrogen, $\mathrm{H}_{\mathrm{r}}$-reversibly adsorbed hydrogen, $\mathrm{H}_{\text {irr }}$-hydrogen adsorbed irreversibly, D-dispersion calculated from hydrogen adsorbed irreversibly. Mean size of iridium particles calculated based on $\mathrm{H}_{\text {irr. }}{ }^{\text {(b) }}$ Catalytic activity expressed as the apparent rate $\left(\mathrm{min}^{-1}\right)$ in moles of toluene reacted per total moles of iridium (determined by XRF measurements).

The results of hydrogen chemisorption measurements show that dispersion depends on the textural properties of the support. The catalysts supported on modified silica with higher surface area show higher dispersion of iridium particles and smaller iridium particles than the catalyst supported on parent silica. The $\mathrm{NH}_{3}-\mathrm{TPD}$ studies for our supports (SiO-F-0.1 and SiO-Cl-0.1-Table 1 and Figure 3) indicated a higher total number of acid centers for SiO-F-0.1 material. The higher acidity of the SiO-F-0.1 surface favors a slightly better dispersion of the iridium active phase. The obtained results are in good agreements with data reported for modified amorphous silica in our previous work [8].

In order to examine the electronic states of the metal functions in iridium catalyst samples, the XPS study was carried out. The binding energy (BE) values for all the catalysts were interpreted after applying the charge correction using $C 1$ s spectra $(B E=284.6 \mathrm{eV})$.

Figure 8 shows the XPS spectra of Ir $4 \mathrm{f}$ region of the Ir/silica catalysts. Two doublets with $4 f_{5 / 2}$ and $4 f_{7 / 2}$ components are observed originated from the spin orbit coupling of the 4f orbital. The doublet separation is of $3.1 \mathrm{eV}$ which correspond well to the standard values for iridium [35]. The XPS measurements confirmed the presence of two different species on the surface: $\operatorname{Ir}^{0}$ and $\operatorname{Ir}^{2+}$. The existence of a metallic $\operatorname{Ir}^{0}$ on the surface is confirmed by the presence of low energy peaks at around $\mathrm{BE}=60.6 \mathrm{eV}$ and $63.7 \mathrm{eV}$ [36]. In addition, the presence of the oxidized form of iridium oxide $\left(\mathrm{IrO}_{2}\right)$ is also observed in all samples (BE of 61.7 and $64.9 \mathrm{eV}$ corresponding respectively to $4 \mathrm{f}_{7 / 2}$ and $4 \mathrm{f}_{5 / 2}$ components) [36,37]. The latter is probably due to the brief air exposure before analysis. Moreover, as could be seen from Table 4, Ir-SiO-F-0.1 catalyst presents much higher extent of the reduced Ir as compared to other samples.
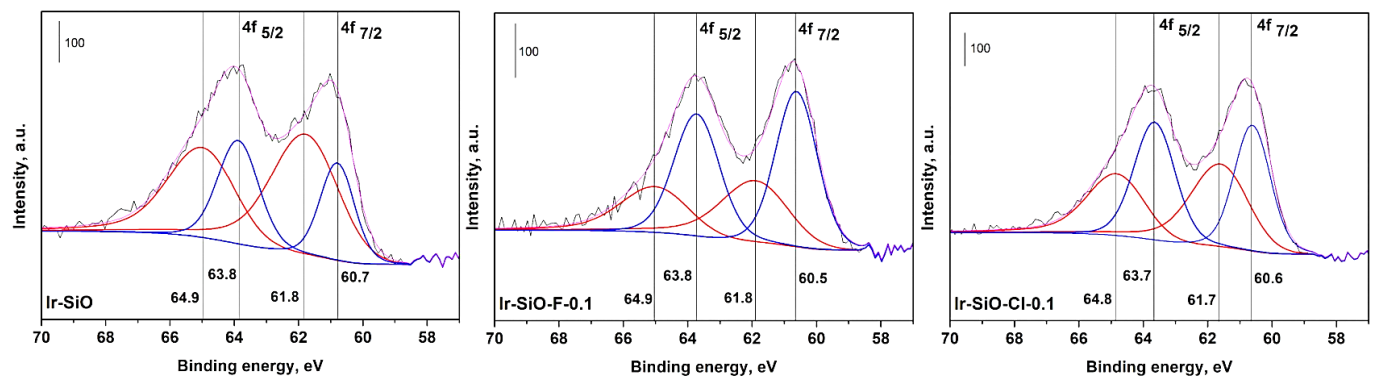

Figure 8. X-ray photoelectron spectra (Ir 4f core levels) for iridium catalysts: Ir-SiO, Ir-SiO-Cl-0.1 and Ir-SiO-F-0.1.

Table 4. $\operatorname{Ir}(0) / \mathrm{IrO}_{2}$ ratio determined from XPS analysis.

\begin{tabular}{cccc}
\hline Iridium Form & Ir-SiO & Ir-SiO-Cl-0.1 & Ir-SiO-F-0.1 \\
\hline $\mathrm{Ir}(0)$ & $36.8 \%$ & $55.1 \%$ & $64.3 \%$ \\
\hline $\mathrm{IrO}$ & $63.2 \%$ & $44.9 \%$ & $35.7 \%$ \\
\hline $\mathrm{Ir}(0) / \mathrm{IrO}_{2}$ & 0.58 & 1.22 & 1.80 \\
\hline
\end{tabular}


The catalytic performance of iridium samples was evaluated in the reaction of toluene (TL) hydrogenation. Hydrogenation of toluene is a simple reaction with just one hydrogenation product, methylcyclohexane $(\mathrm{MCH})$. When the TL hydrogenation was carried out in the presence of silica supports $(\mathrm{SiO}, \mathrm{SiO}-\mathrm{Cl}-0.1$, and $\mathrm{SiO}-\mathrm{F}-0.1)$ no products were observed as a conversion of toluene was null for all supports. This confirms the lack of activity of the supports. Other important parameter that could affect the activity of investigated catalysts is the mass transfer limitations. The Wheeler-Weisz modulus $\left(\varphi^{2} \eta\right)$ evaluated for all iridium sample was lower than 1 within the temperature range used in this work, thus allowing us to neglect diffusional limitations in our experimental conditions [38].

Turnover frequency of toluene hydrogenation (TOF, $\mathrm{min}^{-1}$ ) was calculated based on the number of iridium surface atoms obtained from the volume of chemisorbed hydrogen $\left(\mathrm{H}_{\mathrm{irr}}\right.$-Table 3). Turnover frequencies of the investigated catalysts as a function of temperature reaction are shown in Figure 9. Optimum reaction conditions were established on the basis of our earlier results reported in [39].

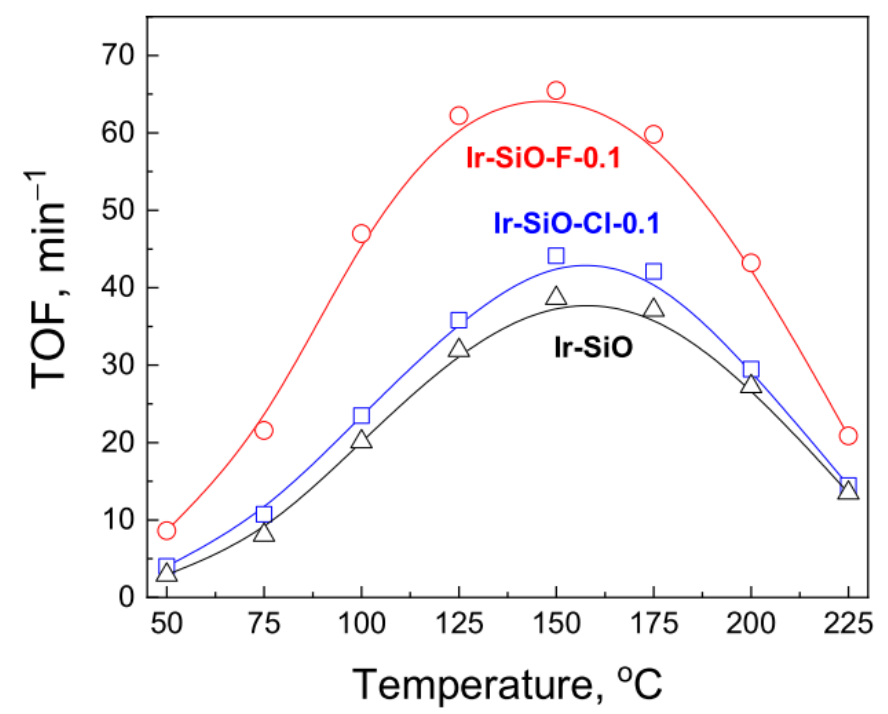

Figure 9. Effect of support on the turnover frequencies of hydrogenation of TL as a function of reaction temperature.

The best catalytic properties in toluene hydrogenation (highest TOF (Figure 9) and the apparent rate (Table 3)) shows iridium catalyst supported on silica modified by $\mathrm{NH}_{4} \mathrm{~F}$. The activity of iridium catalysts increased with increasing reaction temperature, reaching a maximum at $150{ }^{\circ} \mathrm{C}$ for all catalysts. Further temperature increase resulted in a reduction of the activity. The loss of catalytic activity at higher temperatures is due to the occurrence of the dehydrogenation or cracking of $\mathrm{MCH}$ formed during the reaction [40]. The other possibility is a decrease in the number of active sites due to poisoning the surface of the catalyst by carbon deposit obtained by cracking of molecules of reactants [40]. However, in the case of iridium catalysts supported on silica modified with ammonium salts, the cracking products were not observed and the only detected product was methylcyclohexane. It clearly indicates that the loss in catalytic activity at higher temperatures was caused by a reverse reaction, i.e., $\mathrm{MCH}$ dehydrogenation.

The catalytic performance for toluene hydrogenation is affected by the type of support, particularly its textural and acidic properties. The activity of the catalysts increased with the increase of the acidity of the supports. Turnover frequencies at $75^{\circ} \mathrm{C}$ as a function of total hydrogen uptake and density of acid sites are shown in Figure 10a,b. 


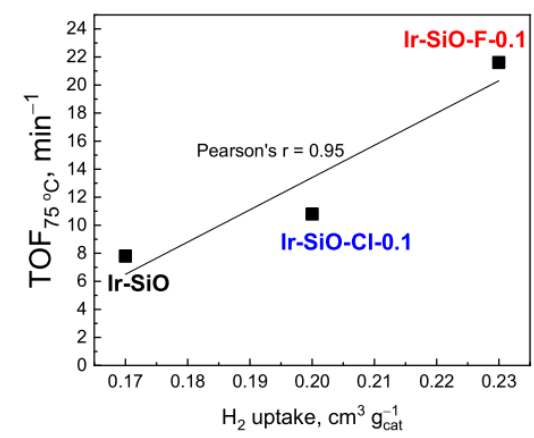

a)
Figure 10. Turnover frequency (TOF) at $75^{\circ} \mathrm{C}$ in toluene hydrogenation reaction as a function of total hydrogen uptake (a) and density of acid sites (b) of iridium catalysts.

The activity of the catalysts in toluene hydrogenation reaction depended on hydrogen uptake. The best catalytic performance, expressed as TOF at $75{ }^{\circ} \mathrm{C}$ was observed for $\mathrm{Ir}-$ $\mathrm{SiO}-\mathrm{F}-0.1$. As was mentioned before, the high activity of Ir-SiO-F-0.1 may be a result of the higher acidity of the support, which can enhance hydrogenation reaction [41] and the relatively higher hydrogen uptake values, indicating also smaller particle sizes of iridium phase. An increase in TOF value is observed with an increase in hydrogen uptake for the iridium catalysts. Due to the fact that the size of iridium crystallites for Ir-SiO-Cl-0.1 and Ir-SiO-F-0.1 catalysts is similar, hence the difference in TOF is not only due to hydrogen uptake but also to the acidity of the supports-Figure $10 \mathrm{~b}$.

As was suggested by the authors [42], the toluene adsorbed on the catalysts surface can be hydrogenated by hydrogen adsorbed through two different mechanisms. Hydrogen adsorbed on the conventional metal active sites and the spillover hydrogen that migrates from the metal sites to the acidic sites. The authors $[5,43]$ reported that Lewis acid sites, being electron-deficient, can easily adsorb aromatic molecules because of their $\pi$-bonds are electron donors. This adsorption occurs with the ring parallel to the surface [44]. The electron-deficient aromatic intermediates like the $\mathrm{MCH}$ intermediate which form on these sites can be easily hydrogenated. Therefore, in order to explain the differences in activity between Ir-SiO-Cl-0.1 and Ir-SiO-F-0.1 catalysts, we conducted toluene adsorption studies.

Figure 11 shows the spectra of gaseous toluene and toluene adsorbed on the iridium catalysts surface. The bands at 1602 and $1496 \mathrm{~cm}^{-1}$ are ascribed to the in-plane skeletal vibration of the aromatic ring. The band at $1385 \mathrm{~cm}^{-1}$ corresponds to the asymmetric deformation of the $\mathrm{C}-\mathrm{H}$ bonding of the methyl group in the toluene molecule whereas the band at $1456 \mathrm{~cm}^{-1}$ is assigned to the stretching of the aromatic ring [45-47]. Chang and Kokes [48] have observed that the absorption bands at 1610 and $1500 \mathrm{~cm}^{-1}$ due to the gaseous toluene shifted to lower wavenumber (1593 and $1487 \mathrm{~cm}^{-1}$, respectively) by adsorption on zinc oxide surface. Serra et al. observed the shift of the absorption bands of toluene towards a lower wavenumber on Cs-exchanged mordenites if compared to the corresponding gas phase toluene bands [49]. According to Lian Su et al. [50], the cause of this shift are changes in electronic distribution and the symmetry of the aromatic ring as a result of toluene interactions with the zeolite structure. On the basis of the cited literature as well as the results presented in Figure 11, it can be concluded that TL is adsorbed through the formation of a $\pi$-complex on surface of investigated catalysts. The intensity of the bands increased with acidity of the support in order $\mathrm{Ir}-\mathrm{SiO}<\mathrm{Ir}-\mathrm{SiO}-\mathrm{Cl}-0.1<$ Ir-SiO-F-0.1. This order correlates with the observed increase in Lewis acidity determined by pyridine adsorption and $\mathrm{NH}_{3}$-TPD measurements. This fact confirms the hypothesis that toluene interacts with the support surface by binding to a Lewis acid site and can be easily hydrogenated by hydrogen adsorbed on the iridium active sites. 


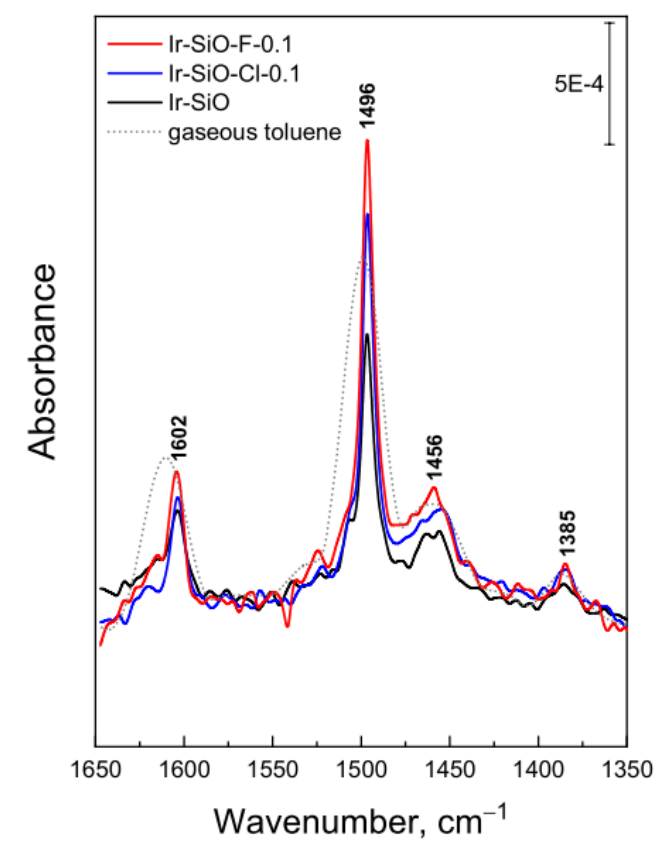

Figure 11. FTIR spectra of gaseous toluene and toluene adsorbed on the surface of iridium catalysts.

\section{Conclusions}

In this work, the influence of acidic and textural properties of modified silica support on the activity of iridium catalysts in the hydrogenation of toluene to methylcyclohexane was determined. It was shown that the type of modifying agent used $\left(\mathrm{NH}_{4} \mathrm{~F}\right.$ or $\left.\mathrm{NH}_{4} \mathrm{Cl}\right)$, as well as its concentration $(0.1$ or $1.0 \mathrm{M})$, had a significant influence on the textural and acid properties of the final supports. The modification with $\mathrm{NH}_{4} \mathrm{~F}$ and $\mathrm{NH}_{4} \mathrm{Cl}$ solutions with concentrations of $0.1 \mathrm{M}$ allows to obtain mesoporous supports with a surface area comparable to the original silica, and their modification leads to the generation on their surface of the Lewis type acid centers of weak and medium strength. The support modified with ammonium fluoride solution $(0.1 \mathrm{M})$ was characterized by a greater proportion of acid centers as well as a larger pore size compared to the systems modified with ammonium chloride. The use of higher concentrations of modifiers $(1.0 \mathrm{M})$ led to a large decrease in the BET surface area. The use of modified silica as iridium supports allowed to obtain a new class of catalysts characterized by high activities in the hydrogenation of toluene, greater than that of the iridium system supported on unmodified $\mathrm{SiO}_{2}$. A comparison of the activity obtained for the best Ir-SiO-F-0.1 catalyst with the results reported in the literature for iridium supported on modified acidic silica [8], alumina [26], as well as SBA-3 or SBA-15 [39], shows that the iridium catalyst supported on modified silica is more promising catalyst.

The hydrogenation activity of catalysts correlated with the acidity of the catalyst supports that influenced not only the size of the iridium particles, but also the efficiency of toluene adsorption. The size of the iridium particles decreased while the amount of adsorbed toluene increased with the acidity of the support in order Ir-SiO; Ir-SiO-Cl-0.1; Ir-SiO-F-0.1. This influenced the hydrogenation properties of the final systems. The highest activity was obtained in the presence of the catalyst supported on silica pretreated with an aqueous $\mathrm{NH}_{4} \mathrm{~F}$ solution characterized by a higher contribution of acid sites and smaller particle size compared to other silica supports investigated.

Supplementary Materials: The following are available online at https:/ /www.mdpi.com/1996-194 4/14/4/968/s1, Detailed experimental procedure-FTIR analysis; $\mathrm{H}_{2}$ chemisorption analysis and toluene hydrogenation reaction; Figure S1: A scheme of the setup for catalytic hydrogenation of toluene; Figure S2: Experimental $\mathrm{NH}_{3}$-TPD profiles (gray curve) from silica supports and peaks corresponding to weak (blue), medium (green) and strong (red) acid centers obtained after decon- 
volution of the experimental curve; Figure S3: Deconvolution of the TPR- $\mathrm{H}_{2}$ profiles of the dried iridium catalysts in the range of first peak; Figure S4: $\mathrm{N}_{2}$ adsorption/desorption isotherms (a) and pore volume distribution as a function of pore size (b) for the iridium catalysts.

Author Contributions: Conceptualization, M.K., E.J., and M.Z.; Methodology, M.K., E.J., and M.Z.; Investigation, M.K., M.P., and R.W.; Writing—original draft, M.K., E.J., and M.Z.; Writing-review and editing, M.Z., E.J., R.W., M.K., and M.P.; Supervision, M.Z.; Visualization, M.P., R.W., and M.Z. All authors have read and agreed to the published version of the manuscript.

Funding: The work was supported by grant No. 2017/27/N/ST5/02042 (Preludium) co-financed by the National Science Center (Poland) (synthesis of materials, physicochemical characteristics and hydrogenation reaction) and by grant No. POWR.03.02.00-00-I023/17 co-financed by the European Union through the European Social Fund under the Operational Program Knowledge Education Development (physicochemical characteristics-XPS and XRF measurements). The author (R.W.) acknowledge the French government through the Programme Investissement d'Avenir (I-SITE ULNE/ANR-16-IDEX-0004 ULNE) managed by the Agence Nationale de la Recherche and Métropole Européen de Lille (MEL) for "CatBioInnov" project.

Institutional Review Board Statement: Not applicable.

Informed Consent Statement: Not applicable.

Data Availability Statement: The data presented in this study are available on request from the corresponding author.

Conflicts of Interest: The authors declare no conflict of interest. The funders had no role in the design of the study; in the collection, analyses, or interpretation of data; in the writing of the manuscript, or in the decision to publish the results.

\section{References}

1. Cleveland, C.J.; Morris, C. Handbook of Energy. In Chronologies, Top Ten Lists, and Word Clouds; Elsevier Inc.: Waltham, MA, USA, 2014; Volume II.

2. Weissermel, K.; Arpe, H.J. Industrial Organic Chemistry, 3rd Completely Revised Edition; Wiley-VCH: Weinheim, Germany, 2008.

3. Lloyd, L. Handbook of Industrial Catalysts. In Fundamental and Applied Catalysis; Twigg, M., Spencer, M., Eds.; Springer: New York, NY, USA, 2011.

4. Lin, S.D.; Vannice, M.A. Hydrogenation of Aromatic Hydrocarbons over Supported Pt Catalysts. I. Benzene Hydrogenation. J. Catal. 1993, 143, 539-553. [CrossRef]

5. Lin, S.D.; Vannice, M.A. Hydrogenation of Aromatic Hydrocarbons over Supported Pt Catalysts. II. Toluene Hydrogenation. J. Catal. 1993, 143, 554-562. [CrossRef]

6. Shafigulin, R.V.; Filippova, E.O.; Shmelev, A.A.; Bulanova, A.V. Mesoporous Silica Doped with Dysprosium and Modified with Nickel: A Highly Efficient and Heterogeneous Catalyst for the Hydrogenation of Benzene, Ethylbenzene and Xylenes. Catal. Lett. 2019, 149, 916-928. [CrossRef]

7. Rahaman, M.V.; Vannice, M.A. The hydrogenation of toluene and o-, m-, and p-xylene over palladium: I. Kinetic behavior and o-xylene isomerization. J. Catal. 1991, 127, 251-266. [CrossRef]

8. Janiszewska, E.; Kot, M.; Zieliński, M. Modification of silica with NH4+ agents to prepare an acidic support for iridium hydrogenation catalyst. Micropor. Mesopor. Mat. 2018, 255, 94-102. [CrossRef]

9. Kot, M.; Kiderys, A.; Janiszewska, E.; Pietrowski, M.; Yang, C.-M.; Zieliński, M. Hydrogenation of toluene over nickel nanoparticles supported on SBA-3 and AlSBA-3 materials. Catal. Today 2020, 356, 64-72. [CrossRef]

10. Glotov, A.; Vutolkina, A.; Pimerzin, A.; Nedolivko, V.; Zasypalov, G.; Stytsenko, V.; Karakhanov, E.; Vinokurov, V. Ruthenium Catalysts Templated on Mesoporous MCM-41 Type Silica and Natural Clay Nanotubes for Hydrogenation of Benzene to Cyclohexane. Catalysts 2020, 10, 537. [CrossRef]

11. Giraldo, L.; Bastidas-Barranco, M.; Moreno-Piraján, J.C. Vapour Phase Hydrogenation of Phenol over Rhodium on SBA-15 and SBA-16. Molecules 2014, 19, 20594-20612. [CrossRef] [PubMed]

12. Cairon, O.; Thomas, K.; Chambellan, A.; Chevreau, T. Acid-catalysed benzene hydroconversion using various zeolites: Brönsted acidity, hydrogenation and side-reactions. Appl. Catal. A Gen. 2003, 238, 167-183. [CrossRef]

13. Chupin, J.; Gnep, N.S.; Lacombe, S.; Guisnet, M. Influence of the metal and of the support on the activity and stability of bifunctional catalysts for toluene hydrogenation. Appl. Catal. A 2001, 206, 43-56. [CrossRef]

14. Kim, J.M.; Chang, S.M.; Kong, S.M.; Kim, K.-S.; Kim, J.; Kim, W.-S. Control of hydroxyl group content in silica particle synthesized by the sol-precipitation process. Ceram. Int. 2009, 35, 1015-1019. [CrossRef]

15. Wojcieszak, R.; Monteverdi, S.; Mercy, M.; Nowak, I.; Ziolek, M.; Bettahar, M.M. Nickel containing MCM-41 and AlMCM41 mesoporous molecular sieves: Characteristics and activity in the hydrogenation of benzene. Appl. Catal. A 2004, 268, 241-253. [CrossRef] 
16. Janiszewska, E. One-pot hydrothermal synthesis of Al-containing SBA-3 mesoporous materials. Micropor. Mesopor. Mat. 2014, 193, 77-84. [CrossRef]

17. Liao, H.; Ouyang, D.; Zhang, J.; Xiao, Y.; Liu, P.; Hao, F.; You, K.; Luo, H. Benzene hydrogenation over oxide-modified MCM-41 supported ruthenium-lanthanum catalyst: The influence of zirconia crystal form and surface hydrophilicity. Chem. Eng. J. 2014, 243, 207-216. [CrossRef]

18. Forni, L.; Fornasari, G.; Giordano, G.; Lucarelli, C.; Katovic, A.; Trifirò, F.; Perri, C.; Nagy, J.B. Vapor phase Beckmann rearrangement using high silica zeolite catalyst. Phys. Chem. Chem. Phys. 2004, 6, 1842-1847. [CrossRef]

19. Bonelli, B.; Forni, L.; Aloise, A.; Nagy, J.B.; Fornasari, G.; Garrone, E.; Gedeon, A.; Giordano, G.; Trifirò, F. Beckmann rearrangement reaction: About the role of defect groups in high silica zeolite catalysts. Micropor. Mesopor. Mater. 2007, 101, 153-160. [CrossRef]

20. Heitmann, G.P.; Dahlhoff, G.; Hölderich, W.F. Catalytically Active Sites for the Beckmann Rearrangement of Cyclohexanone Oxime to $\varepsilon$-Caprolactam. J. Catal. 1999, 186, 12-19. [CrossRef]

21. Lanzafame, P.; Barbera, K.; Perathoner, S.; Centi, G.; Aloise, A.; Migliori, M.; Macario, A.; Nagy, J.B.; Giordano, G. The role of acid sites induced by defects in the etherification of HMF on Silicalite-1 catalysts. J. Catal. 2015, 330, 558-568. [CrossRef]

22. Janiszewska, E.; Kowalska-Kuś, J.; Góra-Marek, K.; Szymocha, A.; Nowińska, K.; Kowalak, S. Modification of silicalite-1 with ammonium compounds aimed at preparation of acidic catalyst for acetalization of glycerol with acetone. Appl. Catal. A 2019, 581, 1-10. [CrossRef]

23. Qiu, C.; Meng, Q.; Panchal, M.; Li, C.; Wu, B. Enhanced Fischer-Tropsch activity in ammonium nitrate pretreated cobalt-silica catalyst. Catal. Commun. 2020, 147, 106149. [CrossRef]

24. Zhao, H.X.; Lü, H.L. Support Modification on the Catalytic Performance of $\mathrm{Co} / \mathrm{SiO}_{2}$ Catalyst in Fisher-Tropsch Synthesis. Adv. Mat. Res. 2013, 850-851, 148-151. [CrossRef]

25. Bergeret, G.; Gallezot, P. Handbook of Heterogeneous Catalysis; Ertl, G., Knözinger, H., Weitkamp, J., Eds.; Wiley-VCH: Weinheim, Germany, 1997.

26. Zieliński, M.; Pietrowski, M.; Wojciechowska, M. New Promising Iridium Catalyst for Toluene Hydrogenation. ChemCatChem 2011, 3, 1653-1658. [CrossRef]

27. Thommes, M.; Kaneko, K.; Neimark, A.V.; Olivier, J.P.; Rodriguez-Reinoso, F.; Rouquerol, J.; Sing, K.S.W. Physisorption of gases, with special reference to the evaluation of surface area and pore size distribution (IUPAC Technical Report). Pure Appl. Chem. 2015, 87, 1051-1069. [CrossRef]

28. Chen, L.; Janssens, T.V.W.; Skoglundh, M.; Grönbeck, H. Interpretation of NH3-TPD Profiles from Cu-CHA Using First-Principles Calculations. Top. Catal. 2019, 62, 93-99. [CrossRef]

29. Pietrowski, M.; Zieliński, M.; Alwin, E.; Gulaczyk, I.; Przekop, R.; Wojciechowska, M. Cobalt-doped magnesium fluoride as a support for platinum catalysts: The correlation of surface acidity with hydrogenation activity. J. Catal. 2019, 378, 298-311. [CrossRef]

30. Hattori, H.; Arudra, P.; Abdalla, A.; Aitani, A.M.; Al-Khattaf, S.S. Infrared Study of Silanol Groups on Dealuminated High Silica MFI Zeolite to Correlate Different Types of Silanol Groups with Activity for Conversion of 1-Butene to Propene. Catal. Lett. 2020, 150, 771-780. [CrossRef]

31. Li, Y.; Zhang, W.; Zhang, L.; Yang, Q.; Wie, Z.; Feng, Z.; Li, C. Direct Synthesis of Al-SBA-15 Mesoporous Materials via Hydrolysis-Controlled Approach. J. Phys. Chem. B 2004, 108, 9739-9744. [CrossRef]

32. Silvennoinen, R.J.; Jylhä, O.J.T.; Lindblad, M.; Österholm, H.; Krause, A.O.I. Supported iridium catalysts prepared by atomic layer deposition: Effect of reduction and calcination on activity in toluene hydrogenation. Catal. Lett. 2007, 114, 135-144. [CrossRef]

33. Hernández-Cristóbal, O.; Díaz, G.; Gómez-Cortés, A. Effect of the Reduction Temperature on the Activity and Selectivity of Titania-Supported Iridium Nanoparticles for Methylcyclopentane Reaction. Ind. Eng. Chem. Res. 2014, 53, 10097-10104. [CrossRef]

34. Wyckoff, R.W.G. Crystal Structures, 2nd ed.; Interscience Publishers: New York, NY, USA, 1963; pp. 7-83.

35. NIST X-ray Photoelectron Spectroscopy Database. Available online: https://srdata.nist.gov/xps/Default.aspx (accessed on 6 October 2020).

36. Wertheim, G.K.; Guggenheim, H.J. Conduction-electron screening in metallic oxides: $\mathrm{IrO}_{2}$. Phys. Rev. B Condens. Matter Mater. Phys. 1980, 22, 4680-4683. [CrossRef]

37. Freakley, S.J.; Ruiz-Esquius, J.; Morgan, D.J. The X-ray photoelectron spectra of Ir, IrO2 and IrCl3 revisited. Surf. Interface Anal. 2017, 49, 794-799. [CrossRef]

38. Weisz, P.B.; Prater, D.C. Interpretation of measurements in experimental catalysis. Adv. Catal. 1954, 6, $143-196$.

39. Kiderys, A.; Kot, M.; Janiszewska, E.; Pietrowski, M.; Yang, C.-M.; Zieliński, M. SBA materials as support of iridium catalyst for hydrogenation reactions. Catal. Today 2020, 356, 178-186. [CrossRef]

40. Zieliński, M.; Pietrowski, M.; Kiderys, A.; Kot, M.; Alwin, E. A comparative study of the performance of Pt/MgF 2 Ir $/ \mathrm{MgF}_{2}$ and $\mathrm{Ru} / \mathrm{MgF}_{2}$ catalysts in hydrogenation reactions. J. Fluorine Chem. 2017, 195, 18-25. [CrossRef]

41. Mojet, B.L.; Miller, J.T.; Ramaker, D.E.; Koningsberger, D.C. A New Model Describing the Metal-Support Interaction in Noble Metal Catalysts. J. Catal. 1999, 186, 373. [CrossRef]

42. Shuwa, S.M.; Jibril, B.Y.; Al-Hajri, R.S. Hydrogenation of toluene on Ni-Co-Mo supported zeolite catalysts. Niger. J. Technol. 2017, 36, 1114-1123. [CrossRef]

43. Masalska, A. Ni-loaded catalyst containing ZSM-5 zeolite for toluene hydrogenation. Appl. Catal. A 2005, 294, 260-272. [CrossRef]

44. Nagao, M.; Suda, Y. Adsorption of Benzene, Toluene, and Chlorobenzene on Titanium Dioxide. Langmuir 1989, 5, 41-42. [CrossRef] 
45. Vittoni, C.; Gatti, G.; Braschi, I.; Buscaroli, E.; Golemme, G.; Marchese, L.; Bisio, C. Toluene Adsorption by Mesoporous Silicas with Different Textural Properties: A Model Study for VOCs Retention and Water Remediation. Materials 2020, 13, 2690. [CrossRef]

46. Sacchetto, V.; Gatti, G.; Paul, G.; Braschi, I.; Berlier, G.; Cossi, M.; Marchese, L.; Bagatin, R.; Bisio, C. The interactions of methyl tert-butyl ether on high silica zeolites: A combined experimental and computational study. Phys. Chem. Chem. Phys. 2013, 15, 13275-13287. [CrossRef]

47. Aspromonte, S.G.; Miró, E.E.; Boix, A.V. FTIR studies of butane, toluene and nitric oxide adsorption on Ag exchanged NaMordenite. Adsorption 2012, 18, 1-12. [CrossRef]

48. Chang, C.C.; Kokes, R.J. Base catalyzed adsorption of toluene by zinc oxide. J. Catal. 1975, 38, 491. [CrossRef]

49. Serra, R.M.; Miró, E.E.; Boix, A.V. FTIR study of toluene adsorption on Cs-exchanged mordenites. Micropor. Mesopor. Mater. 2010, 127, 182-189. [CrossRef]

50. Su, B.L.; Norberg, V.; Martens, J. An infrared study on the location of benzene molecules and cations in Cs+-exchanged EMT zeolite. Micropor. Mesopor. Mater. 1998, 25, 151-157. [CrossRef] 